\title{
Mountain ecosystems in a changing environment
}

\author{
Christian Körner
}

Keywords: Alps, biodiversity, climatic change, $\mathrm{CO}_{2}$, geographical information systems, land use, nitrogen, water

\section{Abstract}

One eighth of the terrestrial surface are mountains, if surface ruggedness is taken as a criterion. Topographic roughness and steep climatic gradients over short distances explain the exceptional biological diversity of mountains around the globe. Habitat diversity also safeguards mountain biota against species losses in case of climatic change, simply because of the mosaics of contrasting micro-environmental conditions that offer short distance escapes. Experimental evidence revealed no benefits of rising atmospheric $\mathrm{CO}_{2}$ concentrations for growth and productivity of alpine plants, but nitrogen deposition bears the risk that slow growing and robust species may become overgrown by vigorous, less robust taxa. Land-use change is likely to exceed the impact of any other environmental change. As exemplified by statistics for the Hohe Tauern region in Austria, almost one third of the current vegetation will undergo dramatic transformations, for no other reason than reduced land use. Land-use policy and land management thus have priority over any other considerations in the context of global change in protected areas.

\section{Introduction}

This essay summarizes some of the major drivers of environmental change in mountain ecosystems to be considered in planning and managing protected mountain areas. It highlights a few examples of plant and ecosystem responses to these changes, and will place these findings, the land-use aspects in particular, in a longer term context. First, I will summarize a few basic characteristics of the world's mountains.

In a strict sense, when rated by their ruggedness, the mountains of the world cover ca. 16 million $\mathrm{km}^{2}$ or $12.5 \%$ of the terrestrial surface outside Antarctica (Körner et al. 2011). Of that area, a global fraction of $2.6 \%$ falls into the life zone above the climatic treeline, the alpine and nival belt. These highest elevation biota are disproportionally rich in species, with an estimated $4 \%$ of all angiosperm taxa above the treeline, largely as a result of topographic diversity (Körner 2004). Treeline is a concept based on tree size and stature of species that can grow at such low temperatures. Quite often trees are absent from the climatic treeline as a result of disturbances (e. g. avalanches, erosion, logging, fire, grazing). So the climatic treeline marks uppermost positions (elevations) of potential tree growth, irrespective of whether trees are present locally.

The treeline is separating the alpine from the montane belt and is thus one of the most prominent biogeographic boundaries globally. It is determined by a minimum warmth during the growing season (a ca. $6{ }^{\circ} \mathrm{C}$ isotherm of the seasonal mean temperature), with the length of the growing season at treeline varying between 3 months at the polar circle and 12 months at the equator (Körner 2012). Its setting by temperature makes it a prime candidate for responses to climatic warming. Obviously, forest boundaries other than those set by climatic conditions offer no predictable response. So the alpine treeline must be clearly distinguished from other forest boundaries.
One of the often overlooked key features of mountains is the trivial fact that the land area is gradually shrinking with increasing elevation. Given the reduction of temperature by ca. $0.55 \mathrm{~K} / 100 \mathrm{~m}$ of elevation, mountains offer an exceptional diversity of thermal life conditions over very short geographical distances. For that reason mountains are often considered an experiment by nature. The close proximity of bioclimatic zones that might otherwise be found across several thousands of kilometres of latitude is one of the main reasons why mountains accumulate more biodiversity per unit land area than their surroundings. Not surprisingly, mountains are hotspots of biological richness worldwide and thus prime target regions for conservation.

What is subsumed under global change includes a broad variety of changes of global dimension, of which five major changes are particularly relevant for high elevation ecosystems:

1. the rise in mean temperature,

2. associated changes in water (and snow) relations,

3. atmospheric $\mathrm{CO}_{2}$ enrichment as a direct influence on vegetation,

4. nitrogen deposition, and

5. changes in land use.

In the following, I will briefly comment on each, with a focus on the European Alps, and will then address land-use changes in more detail.

\section{Atmospheric changes in mountains}

Climatic warming in the Alps is evident from meteorological records (a $1.5 \mathrm{~K}$ warming during the last century), the massive retreat of glaciers and the lengthening of the snow-free season, at least below $2000 \mathrm{~m}$ of elevation (Rebetez \& Reinhard 2008; MeteoSchweiz 2012). Given that mountain climates are considered generally cold, climatic warming is 


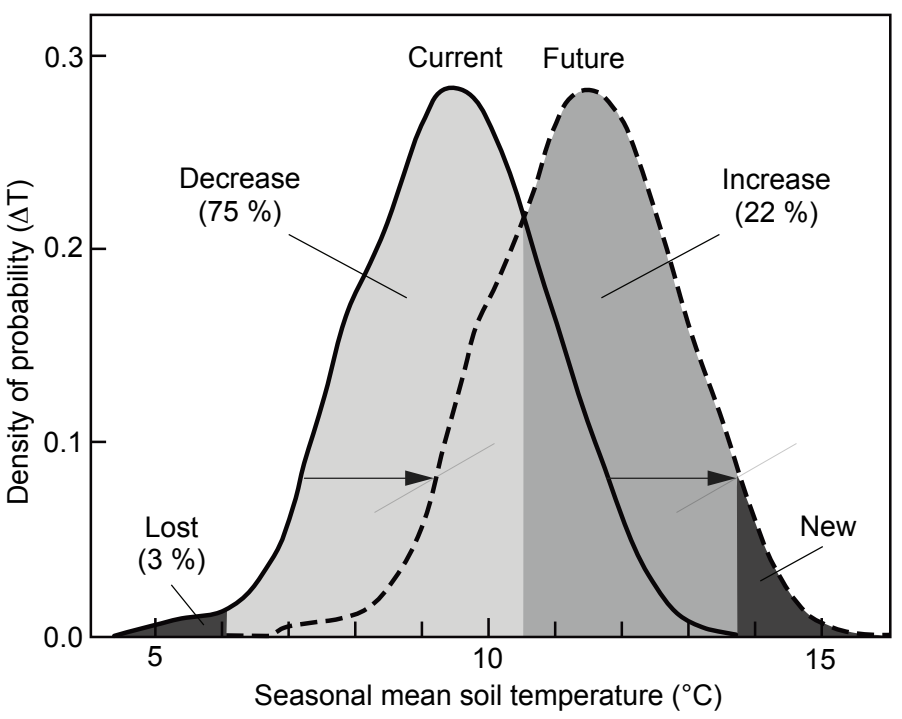

Figure 1 - The frequency distribution of seasonal mean ground temperatures (-3 cm, where most meristems are found) on an alpine slope at ca. $2600 \mathrm{~m}$ measured in 2008 and 2009 compared to a 2 Kelvin warmer climate. As a reference, the seasonal mean air temperature is indicated by a dashed line. Note the reduction of the land area in the cooler categories, but also that hardly any habitat category gets lost (except for the coldest 3\%).

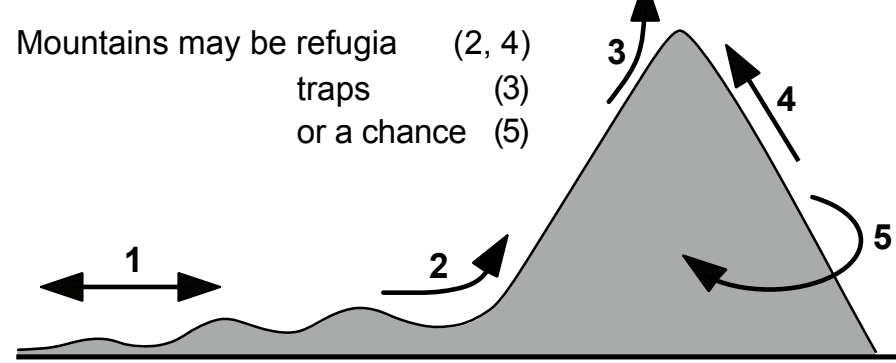

Figure 2 - Escaping from unwanted climatic warming is difficult in the lowlands, offers various options and constraints in mountains, but the most significant avenue, no. 5, is most often overlooked. Contrasting habitat conditions over short distances make mountains ideal refugia under climate change.

thus viewed as the central and most impacting facet of global change in mountains. However, this is too simplistic a view. What weather stations measure is not necessarily what organisms experience. While trees operate very close to ambient temperatures and are indeed experiencing better growth conditions near the treeline than they might have faced during the last 500 years (Paulsen et al. 2000), low stature vegetation produces its own micro-environment.

Using infrared thermography and hundreds of in situ sensors, it could be shown that topography (shelter and exposure to the sun) creates a multitude of climatic niches with temperature ranges that may differ more on a single alpine slope than the magnitude of any worst case climatic warming scenario for the next 100 years (Scherrer \& Körner 2010; Graham et al. 2012, Figure 1).

As a consequence, these low stature plants and their animal and microbial partners are living in a mosaic of life conditions that offers significant microclimatic alternatives across a distance of a few meters. In fact, it was estimated that a $2 \mathrm{~K}$ warming on such a slope would remove merely $3 \%$ of the coldest habitat types, i.e. those inhabited by organisms that are abundant at higher elevations. It may be speculated that the richness in topography-driven climate variation over short distances is one of the reasons why mountains always were refugia when climatic conditions changed (Figure 2). From that it may be expected that the relative proportion of the area of climatic microhabitats will change, but the taxa confined to such habitats are unlikely to become extinct or have to migrate over long distances to find suitable survival conditions. Hence, warming is largely an issue for trees and large animals. Trees have clearly responded to the warmer conditions, as evidenced by dendrochronological data (Paulsen et al. 2000), and it is only a question of time for the treeline to expand upslope into the lower alpine belt (Körner 2012).

Water relations will be affected by climatic change in several ways. Warmer air exerts more evaporative forcing. More precipitation will fall as rain than snow at lower elevations, snow duration will be reduced at elevations below the treeline, but since warmer air also carries more moisture to mountains, the winter snow pack may actually increase at high elevation, with the net balance difficult to predict. What is called heat waves at low elevations commonly translates into particularly good summers at high elevations, given that moisture is not commonly limiting in the upper montane and alpine belt. Hence, periodic drought will exert minor impacts on high elevation biota. On average, the water balance will become more positive as annual precipitation increases, but regional differences may be substantial. A direct water stress-related impact on alpine biota and the treeline is highly unlikely in the Alps. Hence, high elevation conservation areas also provide humid refugia in case of low elevation drought. Montane pastures, increasingly abandoned today, could serve as refugia for herds of domestic animals under extreme drought conditions. This adds to an agro-ecological value in addition to the biodiversity value of these high elevation grasslands.

Direct influences of elevated atmospheric $\mathbf{C O}_{2}$, the prime food of plants absorbed during photosynthesis, had been expected to be particularly influential in high elevation terrain because of the low atmospheric pressure and thus low partial pressure of $\mathrm{CO}_{2}$. However, the evidence to date suggests no or even negative effects on alpine vegetation that is not carbon limited at current atmospheric concentrations (Körner et al. 1997; Inauen et al. 2012). The negative effects that were observed most likely relate to excess carbohydrate exudation by roots that stimulates rhizosphere organisms, which become competitors for soil nutrients, at least during a transition period.

Responses of high elevation forest trees to elevated $\mathrm{CO}_{2}$ were explored in two projects, with one study in montane Picea abies showing absolutely no growth ef- 

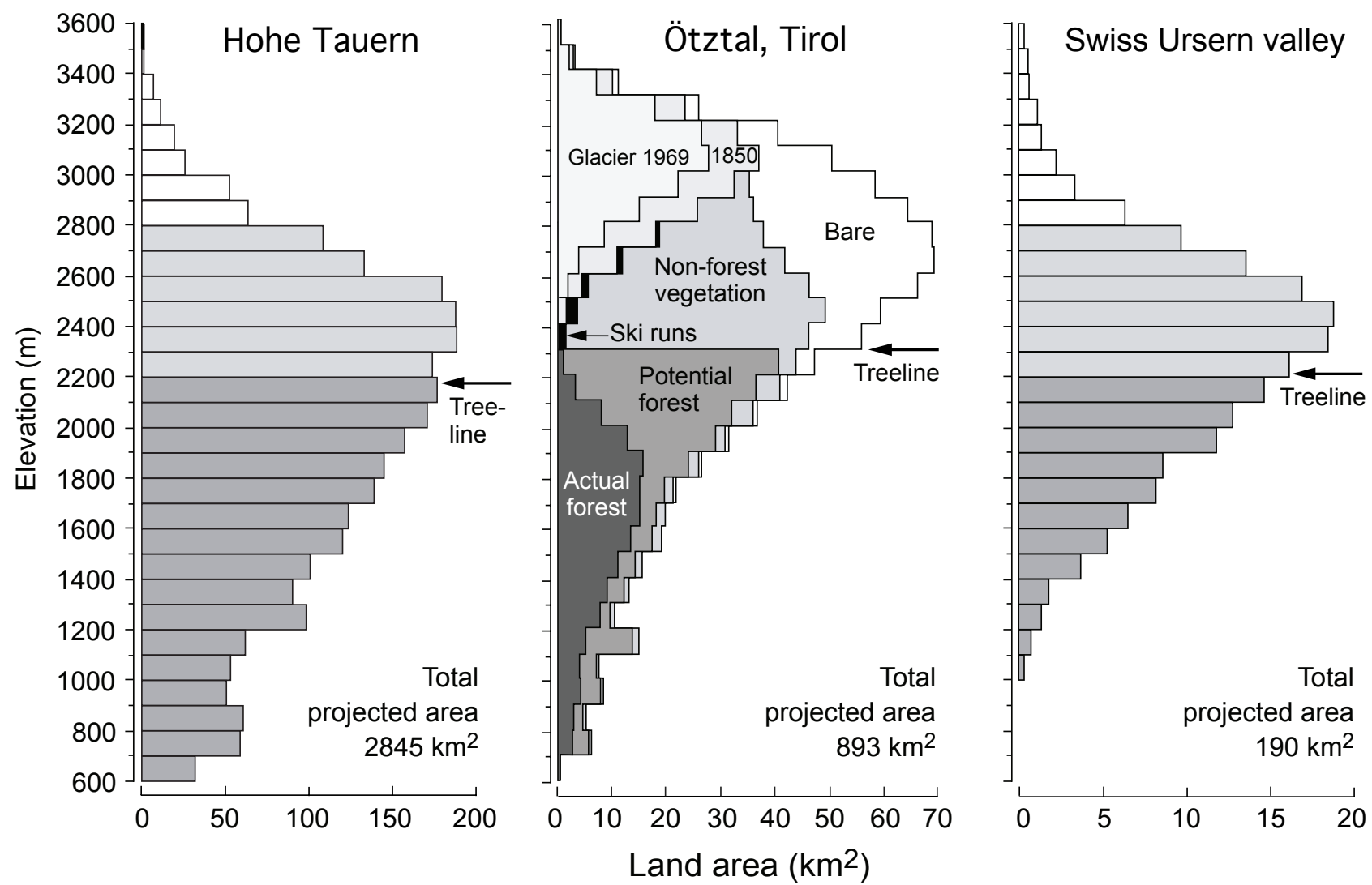

Figure 3 - The elevational stratification of land area in three high mountain regions. (a) The Hohe Tauern region across a N-S transect from the Salzach to the Drau valley; (b) the Ötrtal region in Tyrol, illustrating land cover categories, including new land released by glacier retreat (from Patzelt 1996 as modified in Körner 2003); (c) for the Swiss Ursern valley in the upper Reuss catchment. Note the climatic treeline in each area, separating the montane from the alpine belt.

fect of elevated $\mathrm{CO}_{2}$, but rather a negative effect on tree nutrition for the same reasons as described above (Hättenschwiler \& Körner 1998), and the other one at the treeline, in the case of Pinus cembra with no effect, but a stimulation of growth in isolated saplings of Larix decidua that was tied to particularly warm summers, with a tendency to decline with time. Differential effects were seen in dwarf shrubs, with the montane Vaccinium myrtillus showing a stimulation, but the alpine Empetrum hermaphroditum and Vaccinium uliginosum remaining unresponsive (Dawes et al. 2013). So, while alpine grassland and glacier forefield vegetation is clearly not taking any advantage from elevated $\mathrm{CO}_{2}$, some species in the montane belt may profit, potentially causing some abundance changes. As a caveat, it needs to be remembered that all these experiments are exposing vegetation to a step-change in $\mathrm{CO}_{2}$ at a point in recent history at which $\mathrm{CO}_{2}$ concentration has already increased by $43 \%$ compared to pre-industrial levels. Hence, such experiments do not tell us what effects the past enrichment of the atmosphere with $\mathrm{CO}_{2}$ might have had. Since plants have adjusted over millions of years (since the Miocene) to a mean ca. $240 \mathrm{pm} \mathrm{CO}$ level, it is unlikely that they will take a long-term advantage from rising $\mathrm{CO}_{2}$. Plant growth is in essence controlled by other factors, mainly nutrients.

Nitrogen deposition in the form of $\mathrm{NO}_{\mathrm{x}}$ or $\mathrm{NH}_{4}$ is often considered a lowland problem, closer to in- dustrial / urban areas and intense agriculture. Indeed, mountains receive much less $\mathrm{N}$ deposition than lowlands, but the vegetation is much more sensitive, given its selection for coping with poor nutrition. Hiltbrunner et al. (2005) assessed $\mathrm{N}$ deposition accumulating in snow in the Swiss Central Alps and arrived at an estimated overall current deposition of $5 \mathrm{~kg} \mathrm{~N}$ per hectare and year. Alpine plants have been shown to respond sensitively to rates of nitrogen deposition as low as $5-10 \mathrm{~kg}$ of $\mathrm{N}$ per hectare and year, with species exhibiting different responses (sedges are particularly responsive; E. Hiltbrunner pers. com.; Bobbink et al. 2010). Plant species richness in montane vegetation has recently been shown to decline at $\mathrm{N}$ deposition rates between 10 and $15 \mathrm{~kg} \mathrm{~N} \mathrm{ha}^{-1} \mathrm{a}^{-1}$ (Roth et al. 2013). Hence, $\mathrm{N}$ deposition is clearly more likely to induce changes (Bowman et al. 2012) in alpine vegetation than elevated $\mathrm{CO}_{2}$ levels.

\section{Land-use change in mountains}

Mountain biota are under land-use pressure worldwide (Spehn et al. 2006). The Alps are a region known for its sustainable land-use practices at high elevations. Millennia of traditional land use have in fact produced highly diverse, stable ecosystems of high conservation value (high biodiversity, no soil erosion). Undesired changes go in several directions: 


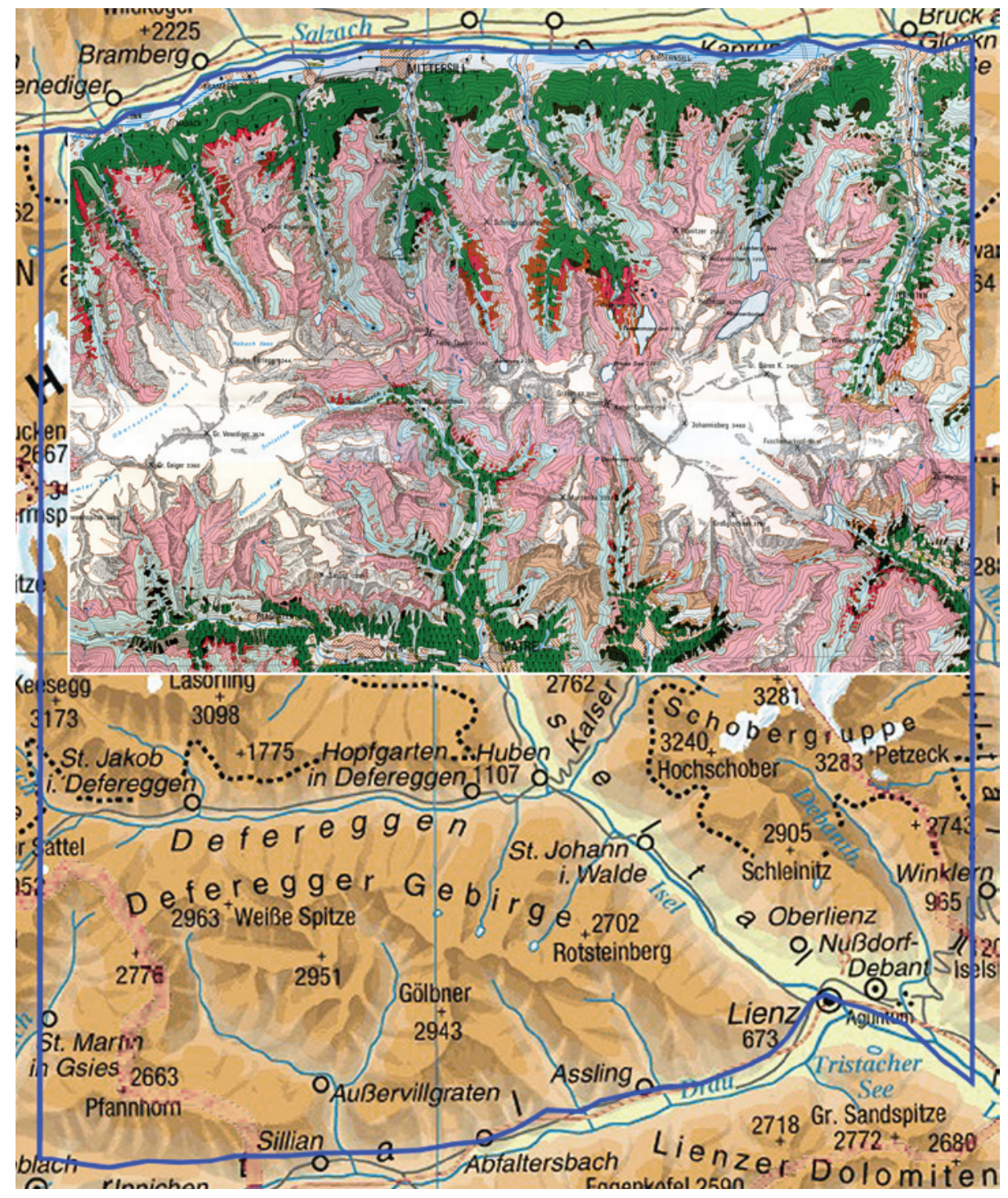

Figure 4 - Geostatistical analysis of mountain terrain should be based on tectonic / geomorphological units (inset showing a transect from the Salzach to the Drau line (see Figure 1a). The coloured map shows the land cover categories as assessed by Ozenda (1975, 1984; see Körner 1989) representing the statistical breakdown visually. The blue frame shows the analysed transect from the Salzach to the Drau river. Background map: (C) Ed. Hölzel, Wien, www. hoelzel.at

1. Destructive over-utilization, followed by soil erosion, a problem of over-populated mountain regions mainly in developing countries.

2. Rapid under-utilization or abandonment, leading to unstable transition stages that provide neither the benefit of the former cultural landscape nor the advantage of the original montane forests (avalanche protection, slope stabilization; Tasser et al. 2003),

3. Easily accessible (valley) terrain gets converted to species-poor, intensively used farmland with high fertilizer input.

Under humid conditions, abandoned high elevation pastures become rapidly encroached by native but invasive species, such as Rhododendron ferrugineum, Calluna vulgaris and other types of small as well as tall shrubs such as Alnus viridis (with accompanying Salix and Sorbus). These novel and extensive shrub- lands are unwanted for several reasons. First, they ruin the former grassland. Second, they slow or even prevent forest succession. Third, in the case of Alnus, $\mathrm{N}_{2}$-fixing symbionts cause ecosystem $\mathrm{N}$ eutrophication, combined with a lush herb layer, effectively suppressing tree seedling establishment and polluting runoff water with excess nitrate. Fourth, these shrublands, the tall type in particular, use more water and reduce catchment value (Inauen et al. 2013; Van den Bergh et al. 2013). These often impenetrable thickets are thus unwanted for agricultural, conservational, hydrological risk mitigation (avalanches) and touristic reasons. They can most effectively be combatted by specialized browsers, such as goats or an old breed of sheep, the Engadine sheep (Bühlmann et al. 2013).

The potential land area likely to undergo such successional stages is large. Geostatistics of land area per elevation demonstrate that the largest fraction of land area in the Alps is situated in the upper montane and 
2

3 5

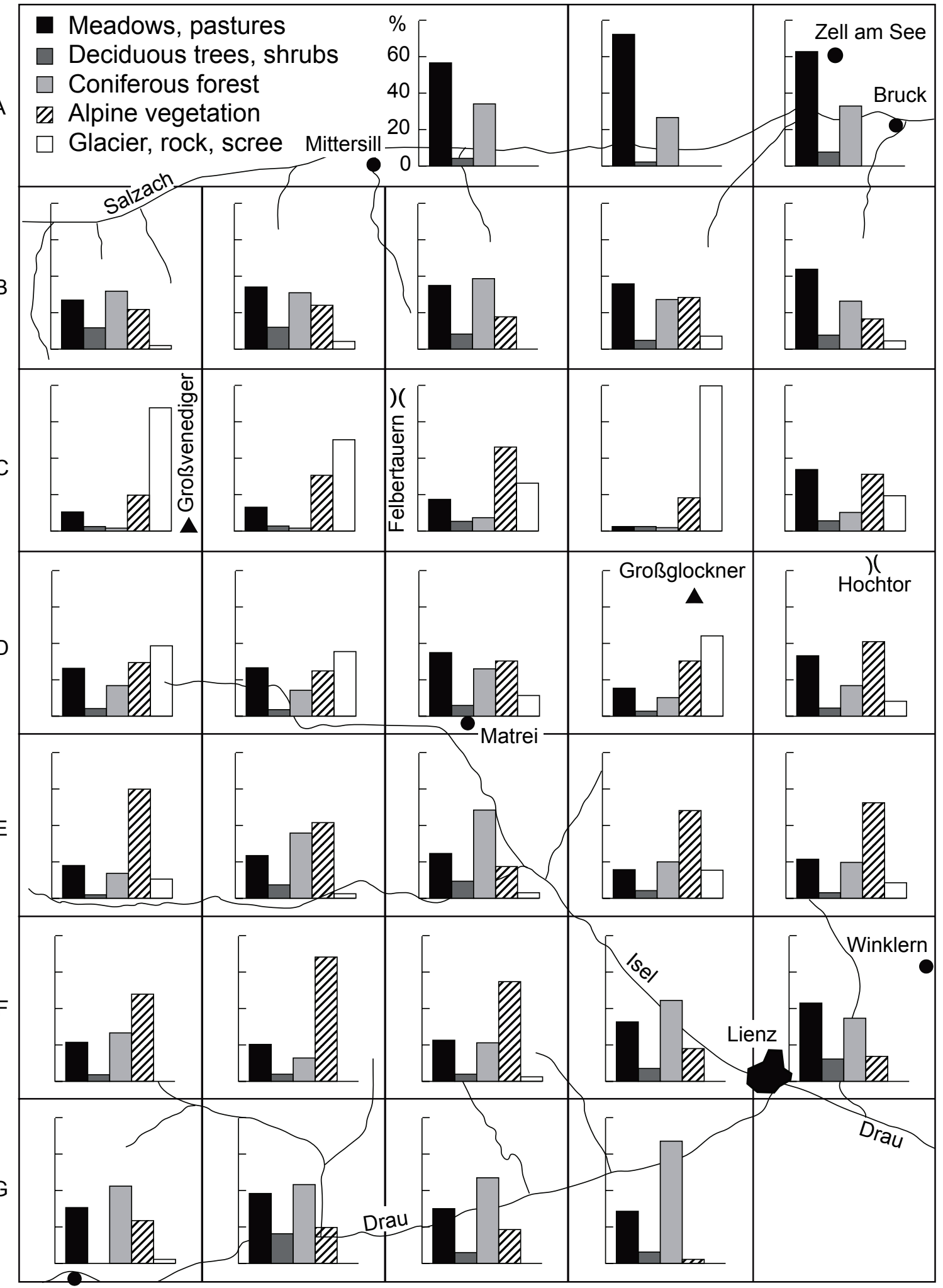

Innichen

Figure 5 - Land cover statistics on a $10 \times 10 \mathrm{~km}^{2}$ grid for the Hohe Tauern region (area as in the inset of Figure 2) using maps as shown in Figure 2 (Körner 1989). Note that the grid covers a N-S cross section across the main divide from the Salzach to the Drau catchment with $a>3 \mathrm{~km}$ amplitude in elevation. 
lower alpine belt, the areas most likely facing declining land use within the coming decades (Figure 3).

Such areal statistics are best not delineated by political boundaries, such as state borders, district or conservation area boundaries, but cover defined topographic elements of the landscape as set by geology and rivers (Figure 4) as exemplified for the Hohe Tauern region. Coarse land cover statistics for this area, as assessed in the 1960s and 1970s, illustrate the situation close to the starting conditions before the most rapid phase of land abandonment is likely to have taken place (Figure 5). As shown by the grid-specific land cover categories, $23 \%$ of the landscape was under extensive agricultural use below the treeline at that time. A large fraction of this terrain will undergo successional land cover changes into shrubland and montane forest. During the mapping of this region in the 1960s and 1970s (total selected area $2845 \mathrm{~km}^{2}=100 \%$ ), $14.8 \%$ were covered by glaciers, rock and scree, $22.9 \%$ by alpine vegetation, $7.8 \%$ by lower alpine dwarf shrub heath, $2.7 \%$ by tall shrubs such as Alnus bush, $23.7 \%$ by coniferous forest, $2 \%$ by deciduous broad-leaved forest, $16.3 \%$ by pastures and $6.7 \%$ by hay meadows. Arable farmland and settlements cover $3 \%$ of this area. If the trends are similar to those in the Swiss Alps (Bühlmann et al. 2013), the tall shrub fraction should have at least doubled since then, and the area covered with forest or tall shrub should approach 30\% at the loss of grassland.

\section{Management implications for conservation}

The classical policy against such near to irreversible land-cover changes takes its motivation largely from preserving a cultural heritage, maintaining farming activities for their own sake or from a conservation point of view (biodiversity). As mentioned above, there is evidence that such land-use changes have negative hydrological implications that have not been accounted for so far. First assessed in a pilot study in the Hohe Tauern region (Körner et al. 1989; Körner 2003), it has recently been confirmed across elevations that land abandonment causes evapotranspiration to increase by about $12 \%$ in the alpine belt, corresponding to similar reductions in runoff and thus diminished hydroelectric potential (Inauen et al. 2013), largely related to the higher leaf area per unit ground area (Van den Bergh et al. 2013). These losses of hydroelectric potential need also be considered in management decisions in protected areas with traditional land use. It were hydrological benefits that led to the establishment of Kosciusco National Park in the Australian Snowy Mountains (Costin 1958).

While the impacts of climatic warming, changes in moisture regimes and nitrogen deposition will be moderate in humid mountains such as the Hohe Tauern region and can be monitored, their causes are supra-national or global. In contrast, the drivers of land cover below the climatic treeline are local or regional and can be managed. The worst decision on land management is no decision, because transitory vegetation after land abandonment often causes unwanted side effects. Most importantly, it severely interferes with natural reforestation. Hence there should be a policy against small and tall shrub encroachment. Of the latter, Alnus viridis (green alder) is most dangerous because of its symbiotic dinitrogen fixation and thus ecosystem eutrophication. Overall, land-use changes are likely to have the greatest impact on high elevation biota in the Alps. Since a great fraction of protected areas in mountains was and partly still is shaped by traditional pastoralism, conservationists are well advised to point at the ecological and conservational drawbacks of land use abandonment and to call for a need to account for hydrological consequences that become effective in the forelands.

\section{Acknowledgements}

This article summarizes results of many years of research, largely funded by the Swiss Science Foundation, the Swiss Federal Office of Agriculture (FOAG) and the Swiss Federal Office of the Environment (FOEN). I thank E. Hiltbrunner for comments on $\mathrm{N}$ deposition and S. Riedl for the artwork.

\section{References}

Bobbink, R., K. Hicks, J. Galloway, T. Spranger, R. Alkemade, M. Ashmore, M. Bustamante, S. Cinderby, E. Davidson, F. Dentener, B. Emmett, J.W. Erisman, M. Fenn, F. Gilliam, A. Nordin, L. Pardo \& W. De Vries 2010. Global assessment of nitrogen deposition effects on terrestrial plant diversity: a synthesis. Ecological Applications 20: 30-59.

Bowman, W.D., J. Murgel, T. Blett \& E. Porter 2012. Nitrogen critical loads for alpine vegetation and soils in Rocky Mountain National Park. Journal of Environmental Management 103: 165-171.

Bühlmann, T., E. Hiltbrunner \& C. Körner 2013. Die Verbuschung des Alpenraums durch die Grünerle. Factsheet, Akademien der Wissenschaften Schweiz. Bern.

Costin, A.B. 1958. The grazing factor and the maintenance of catchment values in the Australian Alps. CSIRO Division of Plant Industry Technical Paper 10: 3-13.

Dawes, M.A., F. Hagedorn, I.T. Handa, K. Streit, A. Ekblad, C. Rixen, C. Körner \& S. Hättenschwiler 2013. An alpine treeline in a carbon dioxide-rich world: synthesis of a nine-year free-air carbon dioxide enrichment study. Oecologia 171: 623-637.

Graham, E.A., P.W. Rundel, W. Kaiser, Y. Lam, M. Stealey \& E.M. Yuen 2012. Fine-scale patterns of soil and plant surface temperatures in an alpine fellfield habitat, White Mountains California. Arctic, Antarctic and Alpine Research 44: 288-295.

Hättenschwiler, S. \& C. Körner 1998. Biomass allocation and canopy development in spruce model eco- 
systems under elevated $\mathrm{CO}_{2}$ and increased $\mathrm{N}$ deposition. Oecologia 113: 104-114.

Hiltbrunner, E., M. Schwikowski \& C. Körner 2005. Inorganic nitrogen storage in alpine snow pack in the Central Alps (Switzerland). Atmospheric Environment 39: 2249-2259.

Inauen, N., C. Körner \& E. Hiltbrunner 2012. No growth stimulation by $\mathrm{CO}_{2}$ enrichment in alpine glacier forefield plants. Global Change Biology 18: 985-999.

Inauen, N., C. Körner \& E. Hiltbrunner 2013. Hydrological consequences of declining land use and elevated $\mathrm{CO}_{2}$ in alpine grassland. Journal of Ecology 101: 86-96.

Körner, C. 1989. Der Flächenanteil unterschiedlicher Vegetationseinheiten in den Hohen Tauern: Eine quantitative Analyse großmaßstäblicher Vegetationskartierungen in den Ostalpen. In: Cernusca, A. (ed.), Veröffentlichungen des Österreichischen MaB-Programms 13: 33-47. Innsbruck.

Körner, C., M. Diemer, B. Schäppi, P. Niklaus \& J. Arnone 1997. The responses of alpine grassland to four seasons of $\mathrm{CO}_{2}$ enrichment: a synthesis. Acta Oecologica 18: 165-175.

Körner, C. 2003. Alpine plant life, $2^{\text {nd }}$ ed. Berlin.

Körner, C. 2004. Mountain biodiversity, its causes and function. Ambio 13: 11-17.

Körner, C. 2012. Alpine treelines. Basel.

Körner, C., G. Wieser \& A. Cernusca 1989. Der Wasserhaushalt waldfreier Gebiete in den österreichischen Alpen zwischen 600 und 2600 m Höhe. In: Cernusca, A. (ed.), Struktur und Funktion von Graslandökosystemen im Nationalpark Hohe Tauern. Veröffentlichung des Österreichischen MAB-Hochgebirgsprogramms Hohe Tauern 13: 119-153. Wien.

Körner, C., J. Paulsen \& E.M. Spehn 2011. A definition of mountains and their bioclimatic belts for global comparisons of biodiversity data. Alpine Botany 121: 73-78

MeteoSchweiz 2012. Klimareport 2011. Bundesamt für Meteorologie und Klimatologie, MeteoSchweiz. Zürich.
Ozenda, P. 1975. Karte der aktuellen Vegetation Tirols, Blatt 12 (Bearbeitung H.M. Schiechtl). Ibid. Band 15.

Ozenda, P. 1984. Karte der aktuellen vegetation Tirols, Blatt 8 (Bearbeitung H.M. Schiechtl). In: Document de Cartographie Ecologique. Band 14. Laboratoire Botanique \& Biologie Végétale, Université, Grenoble.

Patzelt, G. 1996. Modellstudie Ötztal - Landschaftsgeschichte im Hochgebirgsraum. Mitteilungen der Österreichischen Geographischen Gesellschaft 138: 53-70.

Paulsen, J., U.M. Weber \& C. Körner 2000. Tree growth near treeline: abrupt or gradual reduction with altitude? Arctic, Antarctic and Alpine Research 32: 14-20.

Rebetez, M. \& M. Reinhard 2008. Monthly air temperature trends in Switzerland 1901-2000 and 19752004. Theoretical and Applied Climatology 91: 27-34.

Roth, T., L. Kohli, B. Rihm \& B. Achermann 2013. Nitrogen deposition is negatively related to species richness and species composition of vascular plants and bryophytes in Swiss mountain grassland. Agriculture, Ecosystems and Environment 178: 121-126.

Spehn, E.M., M. Liberman \& C. Körner (eds.) 2006. Land use change and mountain biodiversity. Boca Raton.

Tasser, E., M. Mader \& U. Tappeiner 2003. Effects of land use in alpine grasslands on the probability of landslides. Basic and Applied Ecology 4: 271-280.

van den Bergh, T., N. Inauen, E. Hiltbrunner \& C. Körner 2013. Climate and plant cover co-determine the elevational reduction in evapotranspiration in the Swiss Alps. Journal of Hydrology 500: 75-83.

\section{Author}

\section{Christian Körner}

Institute of Botany, University of Basel, Schönbeinstrasse 6, 4056 Basel, Switzerland. Contact: ch.koerner@unibas.ch 